Apidologie, 1971, 2 (1), 67-97.

\title{
DIE FEINSTRUKTUR DER SPERMATHEKA DER BIENENKÖNIGIN (APIS MELLIFICA L.)
}

\author{
La structure fine de la spermathèque de la reine d'abeilles \\ (Apis mellifica L.)
}

\author{
F. RU TTNER, H. ENBERGS und K. KRIESTEN \\ Institut für Bienenkunde, Universität Frankfurt \\ Institut für Anatomie und Physiologie der Haustiere, Universität Bonn
}

\section{SUMMARY}

THE FINE STRUCTURE OF THE HONEY BEE QUEEN SPERMATHECA

The spermathecae of 22 honey bee queens (virgin and inseminated) were examined in an electron microscope. The epithelium, uniform in cell type and in organellae, lies between the enfocuticula and a several layered basal stratum. The endocuticula also is composed of a number of lamellae and contains osmiophilic granula. The epithelial surface and basal region are structured by numerous membrane invaginations, these being more distinct with inseminated and laying queens.

The cytoplasm is densily packed with mitochondria. Large and desintegrated types are especially frequent in inseminated, and laying queens; in these a narrow contact exists between the mitochondria - mainly of oblong shape - and the basal membrane infoldings. GoLGI apparatus and ER are only slightly developed. Osmiophilic bodies are found and here discussed as various types of secundary lysosomes or microbodies.

Apical and basal membrane invaginations, density of mitochondria and abundance of secundary lysosomes are particularly conspicuous in the epithelium of inseminated and laying queens. Together with the absence of a distinct GERL they indicate a transport function of the spermathecal epithelial cells.

It is postulated by the function of the organ and by severing experiments, that a transport occurs through the wall of the spermatheca to maintain the metabolism of the stored spermatozoa. This is strongly supported by the results of this first analysis of the fine structure. 


\section{ZUSAMMENFASSUNG}

Spermatheken von 22 Bienenköniginnen (unbegattet und besamt) wurden elektronenmikroskopisch untersucht. Das im Typ der Zellen sowie ihrer Organellen einheitliche Epithel liegt zwischen einer mehrschichtigen, osmiophile Granula enthaltenden Endocuticula (= innere Spermathekalhülle) und einer ebenfalls aus mehreren Lamellen bestehenden Basalschicht. Epitheloberfläche und Basalzone sind durch zahlreiche Membraneinfaltungen gegliedert. Sie treten bei begatteten und legenden Tieren stärker hervor. Mitochondrien füllen den Zytoplasmaraum fast vollständig aus. Groß- und Desintegrationsformen finden sich besonders bei begatteten und legenden Königinnen; bei diesen besteht auch ein enger Kontakt zwischen vorwiegend länglichen Mitochondrien und basalen Membraneinfaltungen. Golgiapparat und ER sind nur schwach ausgeprägt. Außerdem werden osmiophile Körper beschrieben, die als verschiedene Formen von sekundären Lysosomen bzw. Microbodies diskutiert werden. Apikale und basale Membraneinfaltungen, Mitochondriendichte und Reichtum an sekundären Lysosomen sind im Epithel begatteter und legender Königinnen besonders auffällig. Sie deuten bei gleichzeitigem Fehlen eines ausgeprägten GERL auf Transportleistungen der Thekaepithelzellen hin.

Die aus der physiologischen Leistung des Organs und aus Ausschaltungsexperimenten sich ergebende Forderung, daß durch die Spermathekalwand ein Stofftransport erfolgen muss, erfährt also durch diese erste Analyse der Feinstruktur eine wesentliche Stütze.

Bei Insekten mit einer ausgeprägten Imaginaldiapause liegt häufig zwischen Kopula und Eibefruchtung eine beträchtliche Zeitspanne. Bei der Bienenkönigin, die nur während ihrer ersten Lebenswochen besamt wird, beträgt sie für die zuletzt abgelegten Eier in der Regel 2 Jahre, in Extremfällen 4-5 Jahre. Da sich die Königin fast ständig im Wärmezentrum des Bienenvolkes aufhält, befindet sich das gespeicherte Sperma in einer relativ hohen Temperatur - 34-35o G während der Brutzeit (März-September), 25-300 $\mathrm{C}$ im Winter. Es ist daher anzunehmen, dass es sich bei der Aufbewahrung der lebenden Spermatozoen in der Königin nicht um eine blosse Speicherung im Hohlraum der Spermatheka handelt, sondern um einen sehr spezifischen physiologischen Prozess, der an besonderen Strukturen abläuft.

Die Spermatheka der Bienenkönigin ist ein kugeliger Körper von 1,2 mm $\mathbf{m}^{3}$ Volumen, eingebettet zwischen Ovidukt, Darm und Giftblase (Abb. 1). Die Spermathekaldrüse mündet nicht in die Blase selbst, sondern in den Ductus spermaticus nahe seiner Mündungsstelle in die Spermatheka.

Die Wand der Spermatheka besteht aus einer durchsichtigen Cuticula innen und einem kubischen Epithel (Abb. 2.). Sie ist von einem sehr dichten Netz von Tracheen eingehüllt, das sich leicht ablösen lässt. Verbindungen der Tracheolen zu den Epithelzellen lassen sich bei der Präparation nicht feststellen. Die 5-7 Millionen Spermatozoen im Inneren der Spermatheka liegen in Bündeln dicht gepackt; sie zeigen langsame Bewegungen, synchron in den einzelnen Bündeln.

Neben der Spermathekaldrüse bildet auch das Epithel des D. spermaticus ein Sekret (Camargo und Mello 1970). Lichtmikroskopisch konnte bisher in den Epithelzellen der Spermatheka kein Sekret festgestellt werden, doch finden sich regelmässig und mit dem Alter zunehmend Amyloidkörper im Zellplasma (FIG, 1960). 
Sowohl die Spermathekaldrüse wie die Trachealhülle sind für das Überleben und die Befruchtungsfähigkeit der Spermatozoen unerlässlich. Nach operativer Entfernung beider Drüsenäste legt die Königin nur noch unbefruchtete Eier, obwohl die Spermatozoen noch 75 Tage nach der Operation bei dem Grossteil der Königinnen normale Motilität zeigten (G. Kaniger, 1970). Dass sie funktionell geschädigt waren, ergab sich auch daraus, dass diese Spermatozoen nach instrumenteller Besamung nicht in die Spermatheken anderer Königinnen einwanderten (Rutrner und Koeniger, 1971). Die Entfernung nur eines Drüsenastes führte zu keinen Störungen.

Die operative Entfernung von 50-70\% des Tracheennetzes hatte in allen Fällen sehr rasch die völlige Bewegungslosigkeit der Spermatozoen im Verdünnungstest und die Ablage unbefruchteter Eier durch die Königin zur Folge (G. Koeniger, 1970). Dieser Befund ist überraschend, da bei Zimmertemperatur in Glaskapillaren aufbewahrtes Bienensperma mehrere Wochen lang befruchtungsfähig bleibt (TABer und Blum 1960, Poole und TABer 1969).

Der Gasaustausch kann nur durch die Spermathekalwand erfolgen. Da die Spermatheka frei in der Abdominalhöhle liegt, wäre aber auch ein Stofftransport aus oder in die Haemolymphe denkbar. Im Rahmen der Arbeiten über die Physiologie der Spermatheka erschien daher eine Untersuchung der Feinstruktur der Spermathekalwand geboten.

\title{
MATERIAL UND METHODEN
}

\begin{abstract}
Spermatheken von 6 jungen unbegatteten und 16 ein bis zwölf Monate alten, begatteten oder besamten Bienenköniginnen * wurden entnommen und unmittelbar darauf nach KARNovsKy (1965), in einer Modifikation von Miller u. Henzog (1969) fixiert (2\% Formaldehyd, $2,5 \%$ Glutaraldehyd, 0,025 \% $\mathrm{CaCl}_{2}, 0,09 \mathrm{M}$ Cacodylat-Puffer, $7 \%$ Sucrose ; 2 Std.). Die Nach fixation und Nachkontrastierung des Materials erfolgte in $1 \%$ iger Osmiumsäure (AcetatVeronal-Puffer, $0,05 \mathrm{M}, 4 \%$ Sucrose, $\mathrm{pH} 7,4 ; 1-2 \mathrm{Std}.), 0,5 \%$ Uranylacetat und $1 \%$ iger Phosphorwolframsäure. Entwässerung in Alkohol, Einbettung in Styrol-Methacrylat. Herstellung der Dünnschnitte mit LKB-Ultrotom, Mikroaufnahmen mit dem EM 9a Zeiss (sachzuwendung der Stiftung Volkswagenwk). Zum zytochemischen Nachweis der sauren und alkalschen Phosphatase sowie der Peroxidase wurden die Gomori-Methode nach Barka u. Anderson (1963) und die Methode nach Graham u. Karnovsky (1966) in einer Modifikation von Miller u. Herzog (1969) benutzt.
\end{abstract}

\section{ERGEBNISSE}

Die Thekaepithelzellen aller untersuchten Bienenköniginnen gehören feinmorphologisch einem Zelltyp an. Sie liegen zwischen einer ca. $2 \mu \mathrm{m}$ dicken, intimalen Chitinhaut und einer äußeren, ca $0,8 \mu \mathrm{m}$ starken Basalschicht. Die dieser anliegenden Tracheolen penetrieren das Epithel nicht.

- Die Königinnen stammten zum Grossteil aus dem Institut für Bienenkunde Oberursel. Während der Wintermonate konnten wir dank der Mitarbeit von Herrn und Frau Dr. Eytan (Beer Yaaqov) lebende Königinnen aus Israel beziehen. Einige Königinnen verdanken wir Prof. Drescher, Bonn. 
Die innere Cuticula besteht im Radiärschnitt lumenwärts aus einer schmalen, kompakten Rinde, die Zonen unterschiedlicher Dichte und einen stark osmiophilen Belag aufweist. Epithelwärts folgt ein dickeres, mehrschichtiges Gefüge von fibrillärer Struktur (Abb. 3). Die Rindenschicht liegt nicht plan ihrer Unterlage auf, sondern zeigt feine, unregelmäßig wellenförmige Einbuchtungen, die stellenweise Kanälchen-ähnlich bis zur Oberfläche durchlaufen und eine Art Stomata andeuten können.

Im fibrillären Anteil der Cuticula unterscheidet man je vier bis fünf alternierend elektronendichte bzw. -lichte Lagen in gewöhnlich gleichmäßigen Abständen. Die elektronendichten Schichten bestehen aus nahezu parallelen Fibrillen; diese fächern sich auf und verlaufen dann innerhalb des elektronenlichten Bereichs bogenförmig (Abb. 3). Vor allem im mittleren Abschnitt der fibrillären Cuticula liegen zahlreiche, membranbegrenzte, osmiophile Granula unterschiedlicher Größe (Abb. 3). Sie treten gleichmäßig verteilt oder in größeren Komplexen auf. Häufig zeigen sie Extraktionserscheinungen in Form eines elektronenlichten Bezirks. Im Tangentialschnitt zeigt die fibrilläre Cuticula die gleichen Strukturelemente in unregelmäßiger Anordnung.

Die Cuticula bildet gegenüber dem Epithel keine scharf abgrenzbare Basislinie, sondern folgt mit ihrem Material seinen apikalen Einfaltungen, die sich an den Zellkontaktstellen besonders deutlich markieren (Abb. 6).

Die Epitheloberfläche ist durch Membraneinfaltungen, die abschnittweise auftreten, gegliedert. Dabei verlaufen die einzelnen, unterschiedlich weit ins Zytoplasma hineinziehenden Membranen in geringen Abständen nahezu parallel. Mitochondrien finden zwischen ihnen gewöhnlich keinen Platz (Abb. 5, 11).

Die seitlichen Zytoplasmamembranen benachbarter Zellen verlaufen in gleichmäßigem geringem Abstand und bilden vielfach Einfaltungen, die im oberen bis mittleren Epithelbereich besonders frequent und weitläufig sind (Abb. 2); stellenweise sind regelmäßige Interzellularbrücken zu sehen. Desmosomen treten in unterschiedlich langen Profilen im oberen Zellbereich auf - vor allem unterhalb einer Membranbucht an der apikalen Kontaktstelle zweier Zellen (Abb. 6a). Selten weichen die benachbarten Zellmembranen für kurze Strecken auseinander und lassen dort engbegrenzte interzelluläre Räume entstehen.

Außen wird das Thekaepithel von einer etwa $0,8 \mathrm{um}$ dicken Basalschicht umfaßt, die sich aus mehreren, nahezu parallelen Lamellen aufbaut (Abb. 2); ihre innere Lage folgt den basalen Einfaltungen der Epithelzellen (Abb. 7).

Charakteristisch für die basale Zellregion sind zahlreiche Membraneinfaltungen, die unterschiedlich weit ins Zytoplasma hineinragen. Sie gehen vielfach nach apikal über die Kernzone hinaus und liegen häufig so dicht nebeneinander, daß zwischen ihnen nur schmale Zytoplasmastreifen verbleiben. An anderen Stellen sind ihre Abstände breiter und können Mitochondrien 
enthalten (Abb. 7). Im ganzen gesehen sind die Richtung und die Lagebeziehung der einzelnen Membranen zueinander unregelmäßiger als bei den apikalen Einfaltungen. Apikale und basale Einfaltungen können sich außerhalb des Kernbereichs berühren.

Der Kern der Epithelzellen liegt zentral bis basal. Auf den Anschnitten ist er rundlich bis oval mit gelegentlich tiefen Einbuchtungen seiner Hülle. Die Chromozentren sind bei begatteten Königinnen feingranulär und nahezu gleichmäßig über den Kernraum verteilt (Abb. 2). Nukleolen sind selten. Umgekehrt verhält es sich bei den wenige Tage alten Königinnen : Chromozentren fehlen fast vollkommen, Nukleolen sind sehr zahlreich (Abb. 11). Außer bei den sehr jungen Königinnen ist der Golgi-Apparat schwach entwickelt. Er kann in mehreren Teilkomplexen erscheinen. Seine Membranen sind dicht gepackt, erweiterte Zisternen kaum sichtbar. In seiner Umgebung befinden sich nur einzelne Vesikel. Glattes und rauhes ER treten in einigen Profilen auf; freie Ribosomen sind zahlreicher, vor allem im Thekaepithel der sehr jungen Königinnen.

Außer den Membraneinfaltungen ist ein weiteres charakteristisches Merkmal der Thekaepithelzellen in den Mitochondrien zu sehen. Sie füllen sowohl bei jungen unbegatteten wie auch bei älteren begatteten und legenden Königinnen den Zytoplasmaraum fast vollständig aus. Sie gehören zum CristaTyp. Ihre Anschnitte sind rundlich, oval, länglich oder polymorph. Die Matrix ist osmiophil, die Anzahl der Cristae unterschiedlich. Vor allem an größeren und polymorphen Mitochondrien sind Auflösungserscheinungen mit Vesikel- bzw. Vakuolen-, Fibrillen-, Granulum- oder Kristallbildung nicht selten (Abb. 8, 9). Groß- und Desintegrationsformen von Mitochondrien finden sich besonders im apikalen und mittleren Zellbereich. Dort befinden sich auch rundliche bis ovale Partikel, deren Größe zwischen der von kleinen und großen Mitochondrienquerschnitten schwankt. Ihre feingranuläre Matrix geht fast regelmäßig an der Grenzmembran und seltener an zentralen Stellen in fibrilläre Strukturen über, zwischen denen sich stellenweise auch osmiophile Globuli befinden (Abb. 9). Sie sind besonders häufig im Epithel begatteter und legender Königinnen anzutreffen. Mehrere dieser Gebilde scheinen sich zu größeren Einheiten zu vereinigen (Abb. 9b). Körper dieser Größe zeigen meistens eine fibrilläre und globuläre Organisation (Abb. 8b).

Darüber hinaus liegen im Zytoplasma vereinzelt oder vermehrt in Form von Komplexen wie auch diffus über das Zytoplasma verstreut membranbegrenzte rundliche bis ovale, homogen-osmiophile Granula, die in enger Beziehung zu Membranen und Mitochondrien stehen (Abb. 12). Auffällig und zahlreich ist ihr Erscheinen im Epithel legender Königinnen (Abb. 12), bei denen auch häufig UUbergangsstadien von degenerierenden Mitochondrien zu osmiophilen Granula zu beobachten sind (Abb. 12a).

Im Raum der apikalen und basalen Zellmembraneinfaltungen lassen sich 
feinglobuläre (Abb. 7b) sowie vesikuläre Elemente nachweisen, letztere zuweilen in direkter Abschnürung von den Membranen begriffen.

Mikrotubuli kommen auffallend zahlreich in allen Epithelbereichen vor, gelegentlich in Bündeln gelagert.

Das Thekaepithel der adulten besamten oder begatteten und legenden Königinnen unterscheidet sich von dem der jungen unbegatteten vor allem durch folgende Merkmale : Größere Epithelhöhe, regelmäßigere, zahlreichere und weiter ins Zytoplasma ziehende apikale und basale Zellmembraneinfaltungen und damit größere Membrandichte, zahlreichere und insgesamt mehr längliche, häufig basal-apikal orientierte Mitochondrien mit vermehrten Cristae und engerem Kontakt zu den Membraneinfaltungen, häufigere Desintegrations- bzw. Umwandlungsformen von Mitochondrien, Einlagerung einfach oder komplex gefügter osmiophiler Körper mit fibrillären oder kristallinen Innenstrukturen, vermehrte Ansammlung Microbody-ähnlicher Körper sowie eine hohe Anzahl homogen-osmiophiler Granula (dense bodies) in allen Zytoplasmabereichen.

\section{DISKUSSION}

Die Intima der Spermatheka der Bienenkönigin besteht aus einer Endound Epicuticula und zeigt in ihrem Schichtenaufbau eine ähnliche Struktur, wie sie am Mastdarm der Termiten (Noirot u. NoIrot-Trmothée, 1967) und anderer Insekten (NoIrot u. BAyon, 1969) sowie an der Spermatheka von Periplaneta (Gupta u. Smith, 1969) und Aedes (Clements u. Potter, 1967) vorkommt. Im Unterschied zu diesen beobachtet man in der Epicuticula der Spermatheka der Bienenkönigin hin und wieder unregelmäßige Stomata, die möglicherweise temporär auftreten, und in der Endocuticula zahlreich osmiophile Granula. Bis auf dieses Merkmal entspricht die spermathekale Endocuticula der Honigbiene der des Integuments von Insekten (GLUUD, 1968 ; Stein, 1969 ; Schumacher, 1969).

Feinmorphologisch gleichen die Thekaepithelzellen anderen Epithelzellen mit Transportfunktionen, z.B. denen der Harnkanälchen der Säuger (THoEnes, 1965), den Malpighischen Gefäßen der Insekten (Wessivg, 1965), den Salzdrüzenzellen von marinen Sauropsiden (КомNicк, 1965) sowie den Mastdarmepithelzellen von Termiten (Norrot u. Norrot-Timothée, 1966, 1967) und Analpapillenzellen von Mückenlarven (Coperand, 1964). Von den eigentlichen Epithelzellen der Spermatheka von Periplaneta unterscheidet sie die gleichmäßige Verteilung der Mitochondrien im Zytoplasmaraum und von denen der Aedes vor allem der Reichtum an Mitochondrien.

Die Membran- und Mitochondrienfülle sowie deren Verlauf und Form führen zwar zu einem sehr engen Kontakt dieser Organellen, besonders bei begatteten Königinnen (Abb. 2, 7b, 12a, c); zur Ausbildung einer besonders 
geformten Kontaktzone, wie sie Noгrot u. Noгrot-Tiмотне́E (1967) am Intestinum von Termiten und Copeland (1964) an der Analpapille von Mückenlarven beobachteten, kommt es aber in den Spermathekaepithelzellen der Bienenkönigin nicht.

Auffällig sind die zahlreichen Umwandlungs- bzw. Desintegrationsformen von Mitochondrien im Thekaepithel der Honigbiene, die bei Periplaneta und Aedes nicht beschrieben wurden. Von ihnen aus sind Übergänge zu den homogenen osmiophilen Granula (dense bodies) sowie den größer und vielfach komplexer organisierten Körpern mit verschiedenen Innenstrukturen möglich (Abb. 8, 9, 12).

Die hauptsächlich im Epithel begatteter Königinnen anzutreffenden rundlichen bis ovalen Gebilde mit feingranulärer Matrix und peripheren oder zentralen fibrillären Anteilen (Abb. 9a) stehen feinmorphologisch zwischen Zytosomen, Microbodies und sekundären Lysosomen. Dafür, daß es sich bei diesen Partikeln um Microbodies handeln kann, spricht der positive Ausfall der Peroxidase-Reaktion (Abb. 12d); die Zuordnung dieser Reaktion zu einer bestimmten Gruppe der verschiedenen Granula war allerdings nicht möglich. De Duve u. Baudhuin (1966) machten für die Microbodies u.a. folgende Stoffwechselrollen wahrscheinlich : Hilfsorgane der Kohlehydratoxidation, Beteiligung an der Gluconeogenese und an der Energieproduktion. Man diskutiert - wenn auch nicht unwidersprochen -, daß Microbodies aus Zytosomen entstehen und Vorläufer von Mitochondrien sein sollen (HrubaN u. Rechaigl, 1969). Außerdem denkt man an eine mögliche Transformation der Microbodies zu Lysosomen. Andererseits kann man die beschriebenen Formationen morphologisch auch als primäre Zytoplasmademarkierungen (Zytosome) ansehen, die in weiteren Schritten - u.a. auch unter Verschmelzung in verschiedene Formen sekundärer Lysosome übergehen können. Funktionell kann man diese als Autophagosome bzw. Cytosegresome, Heterophagosome, Telolysosome bzw. Residualbodies ansehen. Sie reagieren ganz oder teilweise Phosphatase-positiv (saure und alkalische Phosphatase), die Partikel mit kristallinen Einschlüssen nur in den Randbezirken (Abb. 12).

Die sekundären Lysosome könnten vorübergehend im Dienst von Stoffwechselleistungen stehen. Aus Gründen eines angeborenen oder erworbenen Enzymmangels bzw. -defekts mögen einige von ihnen durch Anhäufung nicht umsetzbarer Stoffe an Umfang zunehmen und sich mangels einer Defäkations- bzw. Exozytosemöglichkeit im Epithel als Restkörper (residual bodies) anreichern (De Duve, 1969; Lockshin, 1969 ; Daems et al., 1969 ; Maunsbach, 1969; Ericsson, 1969). Sie dürften mit den von FYg (1960) beschriebenen Amyloidkörpern identisch sein. Ob sie im Epithel älterer begatteter und legender Königinnen - wie von FYg vermutet - die Zellfunktion im Sinn einer Speicherkrankheit beeinträchtigen, ist noch offen. Weiterhin bleibt zu klären, ob die im Thekaepithel von legenden Königinnen besonders vermehrt 
auftretenden Lysosomen (dense bodies) mit bestimmten Stoffwechselleistungen - wie Transport - in Zusammenhang stehen oder lediglich Ausdruck eines Zellumbaus sind. Miller u. Palade (1966) demonstrierten an Mäusenieren die Bedeutung der Lysosomen bei der renalen Proteinabsorption. LocKsHin (1969) weist auf ihre Rolle bei der Eientwicklung von Insekten hin und vermutet, daß sie beim Transport der Blutproteine in den Dotter und beim Umwandlungsproze $\beta$ dieser Proteine in Dottermaterial beteiligt sein müssen.

Insgesamt gesehen zeigt das Thekaepithel der Bienenkönigin feinmorphologische Merkmale aktiver Zellen, die bei einer vergleichenden Betrachtung junger unbegatteter und älterer begatteter und legender Königinnen in ihrer Expressivität zunehmen. Die zahlreichen Nukleolen in den Thekaepithelzellkernen sehr junger Königinnen sowie die große Zahl freier Ribosomen bei gleichzeitiger Abwesenheit eines ausgeprägten ER und Golgi- Apparates sind Kennzeichen sich noch entwickelnder Zellen. Versucht man aus diesen ersten feinmorphologischen Befunden auf die mögliche Funktion der Spermatheka zu schließen, so kann diese nicht allein passiv-mechanisch Depotorgan für den Samen sein, sondern muß zusätzlich noch aktiv an Stoffwechselprozessen beteiligt sein. Ausgedehnte apikale und basale Zellmembraneinfaltungen, die Mitochondriendichte sowie die zahlreichen sekundären Lysosomen bei gleichzeitigem Fehlen eines ausgeprägten GERL deuten darauf hin, daß bei der Funktion der Spermatheka nicht Produktions-, sondern vielmehr Transportvorgänge im Vordergrund stehen müssen. Von der Feinstruktur der Theka her wären sie sowohl lumenwärts wie tracheolenwärts möglich. Welche Richtung hier bevorzugt wird und welche Stoffe teilnehmen, ist in weiteren gezielten Untersuchungen zu bestimmen.

Eingegangen im November 1970.

Reçu pour publication en novembre 1970.

Frau Ch. Pörtener, Bonn, danken wir für ihre technische Assistenz. 


\section{RÉSUMÉ}

La spermathèque de 22 reines d'abeilles (soit vierges soit fécondes) a été étudiée en microscopie électronique. L'épithélium, homogène par le type des cellules qui le constituent ainsi que par ses organites, est situé entre une endocuticule à plusieurs couches contenant des grains osmiophiles ( = enveloppe interne de la spermathèque) et une couche basale également constituée de plusieurs lamelles. La surface épithéliale et la zone basale sont divisées par les nombreux replis de la membrane. Ces replis sont plus apparents chez les reines fécondes et en ponte. Les mitochondries remplissent l'espace cytoplasmique de façon presque totale. Les grandes formes et les formes de désintégration se trouvent particulièrement chez les reines fécondées et en ponte; chez celles-ci il existe également un contact étroit entre des mitochondries qui sont en majorité allongées et les replis basaux de la membrane. Appareil de Golgi et réticulum endoplasmatique sont peu marqués. Par ailleurs on décrit des corps osmiophiles dont la nature est discutée; il s'agirait de formes diverses de lysosomes secondaires c'est-à-dire de microbodies. Les replis apicaux et basaux de la membrane, la densité des mitochondries et la richesse en lysosomes secondaires sont particulièrement frappants dans l'épithélium des reines fécondées et en ponte. Ces caractères et l'absence concommitante d'un GERL marqué indiquent pour les cellules épithéliales de la thèque une faculté de véhiculer les substances.

Le fait qu'il soit nécessaire pour la paroi de la spermathèque de permettre les transports de substances, fait établi par les performances physiologiques de l'organe ainsi que par les expériences d'ablation, trouve une nette confirmation dans cette première analyse de sa structure fine.

\section{LITERATUR}

Barka T., Anderson P. J., 1962. Histochemical methods for acid phosphatase using hexazonium pararosanilin as coupler. J. Histochem. Cytochem., 10, 741-753.

Camargo J. M. F., Melco E., 1970. Anatomy and histology of the genital tract, spermatheca, spermathecal duct and glands of Apis mellifera queens. Apidologie, 1, 351-373.

Cléments A. N., Potter S. A., 1967. The fine structure of the spermathecae and their ducts in the mosquito Aedes aegypti. J. Insect. Physiol., 13, 1825-1836.

Copeland E., 1964. A mitochondrial pump in the cells of the analpapillae of mosquito larvae. J. Cell Biol., 23, 253-263.

DaEmS W. Th., Wisse E., Bredenoo P., 1969. Electron microscopy of the vacuolar apparatus. 64-112. In : Lysosomes in Biology and Pathology, I, ed. Dingle J. T. and Fell H. B., North-Holland Publishing Company, Amsterdam. London.

DE Duve C., 1969. The lysosome in retrospect. ibid. 3-40.

De Duve C., Baudhuin, 1966. Peroxisomes (Microbodies and related particles). Phys. Rev., 46, 323-357.

Erisscon J. L. E., 1969. Mechanism of cellular autophagy. 345-394. In : Lysosomes in Biology and Pathology II, ed. Dingle J. T. and Fell H. B., North-Holland Publishing Company, Amsterdam, London.

Fyc W., 1960, Uber die Ablagerung von Amyloid im Samenblasenepithel der Bienenkönigin (Apis mellifica L.) . Entomologie, 45, 415-420.

GluUd A., 1968. Zur Feinstruktur der Insektencuticula. Ein Beitrag zur Frage der Wanzencuticula. Zool. Jb. Anat., 85, 191-227. 
Graham R. C., Kannovsky M. J., 1966. The early stages of absorption of injectid horseradish peroxidase in the proximal tubules of mouse kidney : ultrastructural cytochemistry by a new technique. J. Histochem. Cytochem., 14, 291-302.

Gupta B. L., Sмrтн D. S., 1969. Fine structural organization of the spermatheka in the cockroach, Periplaneta americana. Tissue + Cell 1, 295-324.

Hruban Z., Rechcige M., 1969. Microbodies and related particles Morphology, Biochemistry and Physiology. Academic Press, New York and London.

KARNovsky M. J., 1965a. A formaldehyde-glutaraldehyde fixative of high osmolality for use in electron microscopy. J. Cell Biol., 27, 137A.

Kaniger G., 1970. Bedeutung der Tracheenhülle und der Anhangsdrüse der Spermatheka für die Befruchtungsfähigkeit der Spermatozoen in der Bienenkönigin (Apis mellifica L.). Apidologie, 1, 55-71.

Komvick H., 1965. Funktionelle Morphologie von Salzdrüsenzellen. 289-314. In : Sekretion und Exkretion, Springer-Verlag, Berlin, Heidelberg, New York.

Lockshin R. A., 1969. Lysosomes in insects. 363-391. In : Lysosomes in Biology and Pathology I, Dingle J. T. und Fell H. B., North-Holland Publishing Company, Amsterdam, London.

Maunsbach A. B., 1969. Functions of lysosomes in kidney cells. 115-154. Ibid.

Miller F., Herzoc V., 1969. Die Lokalisation von Peroxydase und saurer Phosphatase in eosinophilen Leukocyten während der Reifung. Elektronenmikroskopisch-cytochemische Untersuchungen am Knochenmark von Ratte und Kaninchen. Z. Zellforsch., 97, 84-110.

Miller F., Palade G. E., 1964. Lytic activities in renal protein absorption droplets. An electron microscopical cytochemical study. J. Cell. Biol., 23, 519-552.

Norrot Ch., Bayon C., 1969. La cuticule proctodéale : mise en évidence de c dépressions épicuticulaires ", par le microscope électronique à balayage. C. R. Acad. Sc. Paris, 269, 996-999.

Noirot Ch., Noinot-Tmothés C., 1966. Revêtement de la membrane cytoplasmique et absorption des ions dans les papilles rectales d'un Termite (Insecta, Isoptera). C. $R$. Acad. Sc. Paris, 263, 1099-1102.

Noinot Ch., Noinor-Tıмoтhée C., 1967. L’épithélium absorbant de la panse d'un Termite supérieur. Ultrastructures et rapport avec la symbiose bactérienne. Ann. Soc. Ent. Fr., 3, $577-592$.

Noirot Ch., Noinot-Timothée, Kovoor J., 1967. Revêtement particulaire de la membrane plasmatique en rapport avec l'excrétion dans une région spécialisée de l'intestin moyen des Termites supérieurs. C. R. Acad. Sc. Paris, 264, 722-725.

Norrot-Timormée C., Nornot Ch., 1967. Liaison de mitochondries avec des zones d'adhésion intercellulaires. J. Microscopie, 6, 87-90.

Poole H. K., Taber St. III, 1969. A method of in vitro storage of honev-bee semen. $A m$. Bee J., 109, 420-421.

Porten K. R., 1966. Cytoplasmic microtubules and their functions. 308-345. In : Principles of Biomolecular Organization. Ciba Foundation Symposion, Walstenholme G. E. W. und O'Connor M., London und Churchill.

Ruttner F., Koeniger G., 1971. Die Füllung der Spermathekad er Bienenkönigin. Aktive Wanderung oder passiver Transport der Spermatozoen? Z. vergl. Physiologie 72, 411-422.

Schumacher R., 1969. Zur funktionellen Morphologie der imaginalen Duftdrïsen zweier Landwanzen : Pyrrhocoris apterus L. und Dysdercus intermedius Dist., Geocorisae, Fam. : Pyrrhocoridae. Dissertation Bonn.

Sekнon S. S., Beams H. W., 1969. Fine structure of the developing trout erythrocytes and thrombocytes with special reference to the marginal band and the cytoplasmic organelles. Am. J. Anat., 125, 353-374.

Stein G., 1969. Uber den Feinbau der Duftdrüsen von Heteropteren. Die hintere larvale 
Abdominaldrüse der Baumwollwanze Dysdercus intermedius Dist. (Insecta, Heteroptera). Z. Morph. Tiere, 65, 374-391.

TAber St. III, Blum M. S., 1960. Preservation of honey bee semen. Science, 131, 1734-1735.

Thoenes W., 1965. Transportwege in den Harnkanälchen der Säugerniere. 315-342. In : Sekretion und Exkretion, Springer-Verlag, Berlin, Heidelberg. New York.

WeInReB E. L., WeInReB S., 1965. Studies on the fine structure of teleost blood cells. II. Microtubular elements of erythrocyte marginal bands. $Z$. Zellforsch., 68, 830-836.

Wessing A., 1965. Die Funktion der Malpighisehen Gefäße. 228-268. In : Sekretion und Exkretion, Springer-Verlag, Berlin, Heidelberg, New York.

Anschrift der Verfasser

Prof. Dr. F. Rutrinen, Institut f. Bienenkunde, 637 Oberursel.

Dr. H. Enbergs, Dr. K. Kriesten, Institut f. Anatomie und Physiologie der Haustiere, 53 Bonn, Katzenburgweg 7.9. 


\section{TAFEL I}

Авв. 1. - a) Situs der Spermatheka im Abdomen der Bienenkönigin. Be Bursa copulatrix, Dr Spermathekaldrüse, G Giftblase, m0, 10 medianer u. lateraler Ovidukt, Ov Ovarium, Sp Samenpumpe, St Stachel, Spth Spermatheka, V Vagina, V. v. Valvula vaginalis.

Aвв. 1. - b) Schnitt durch die Spermatheka einer besamten Königin (im Lichtmikroskop). A Spermathekaldrüse, Ep Epithelium, Sp Spermatozoen, Tr Tracheenhülle. x 80. Photo W. Fyg.

\section{PLANCHE I}

Fig. 1. - a) Situation de la spermathèque dans l'abdomen de la reine. Bc, Bursa copulatrix. Dr, glande de la spermathèque. $G$, poche à venin. $\mathrm{mO}, 10$, oviducte médian et oviducte latéral. Ov, ovaire. Sp, pompe à sperme, St, aiguillon. Spth, spermathèque. $V$, vagin. V. $v$, valvule vaginale.

b) Coupe au travers de la spermathèque d'une reine fécondée (microscopie optique). A, glande de la spermathèque. Ep, épithélium. Sp, spermatozoïdes. Tr, enveloppe trachéenne. x 80. Photo W. Fyg. 


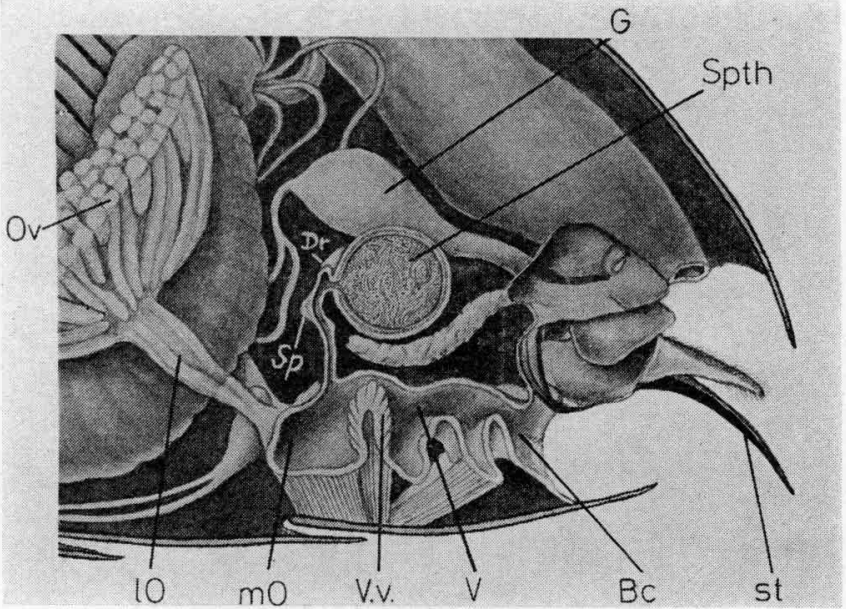

AвB. 1a

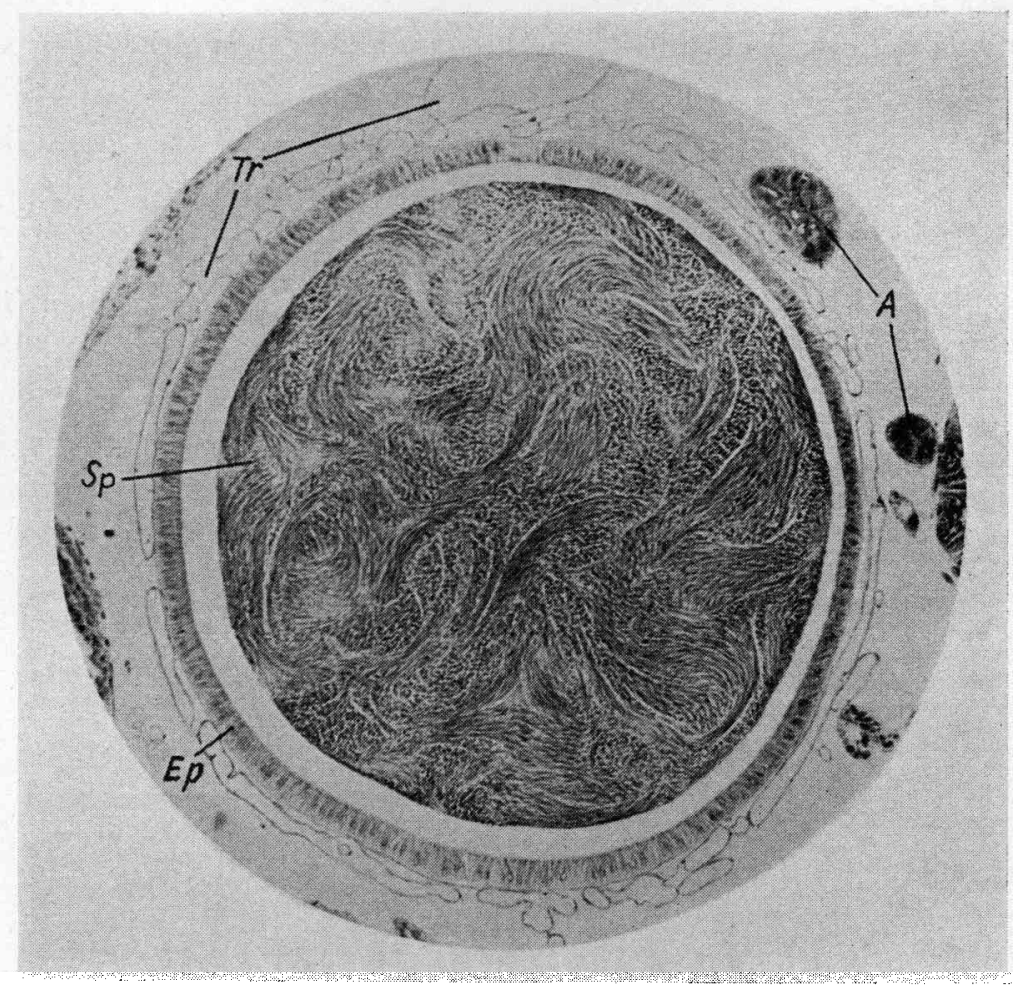

Aв8. 1 b

F. Ruttner, H. Enbergs, K. Kriesten 


\section{TAFEL II}

Aв8. 2. - Ubersicht über das Spermathekaepithel einer vor 3-5 Monaten begatteten Königin.

Cuticula (C), Basalschicht (B), Kerne (N), Tracheolenepithel (Tr). x 6300.

\section{PLANCHE II}

Fig. 2. - Vue d'ensemble de l'épithélium de la spermathèque d'une reine fécondée depuis 3 d 5 mois. $\mathrm{C}$, euticule. $\mathrm{B}$, couche basale. $\mathrm{N}$, noyau. $\mathrm{Tr}$, enveloppe trachéolaire. $\times 6300$. 


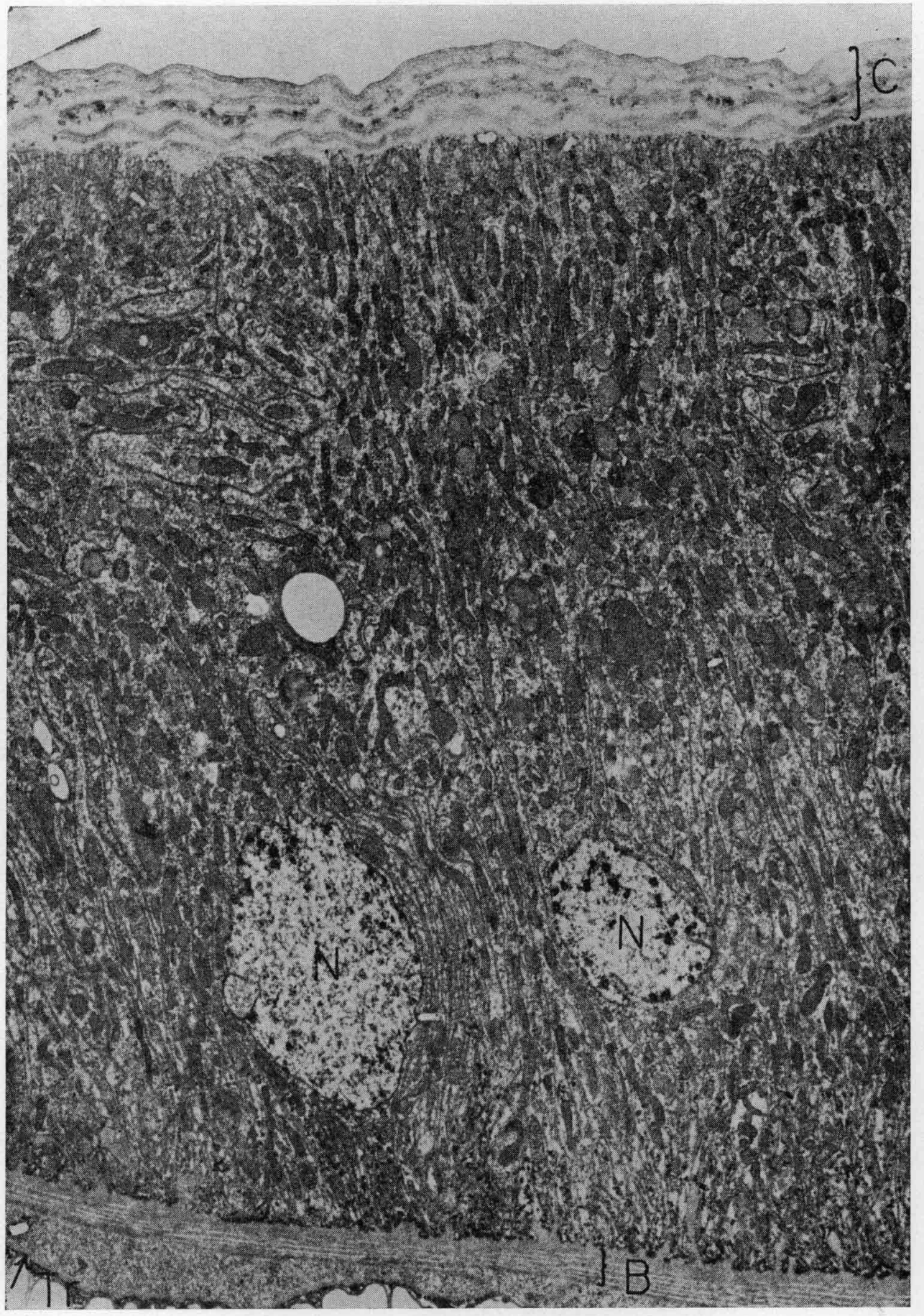

F. Ruttner, H. Enbergs, K. Kriesten 
Aв8. 3. Struktur der Cuticula der Spermatheka.

a) Endocuticula (Ec), paralleler (p) und bogenförmiger (b) Verlauf der Fibrillen, Epicuticula (Ep), Epithel (E). x 35000.

b) Epicuticula (Ep) mit “ Stomata » (St). x 105000.

\section{PLANCHE III}

Fig. 3. - Structure de la cuticule de la spermathèque.

a) $E c$, endocuticule. Orientation parallèle $(p)$ ou arquée (b) des fibrilles. $\mathrm{E} p$, épicuticule. $\mathrm{E}$, épithélium. $\mathrm{x} 35000$.

b) Ep, épicuticule avec « stomate » (St). x 105000. 

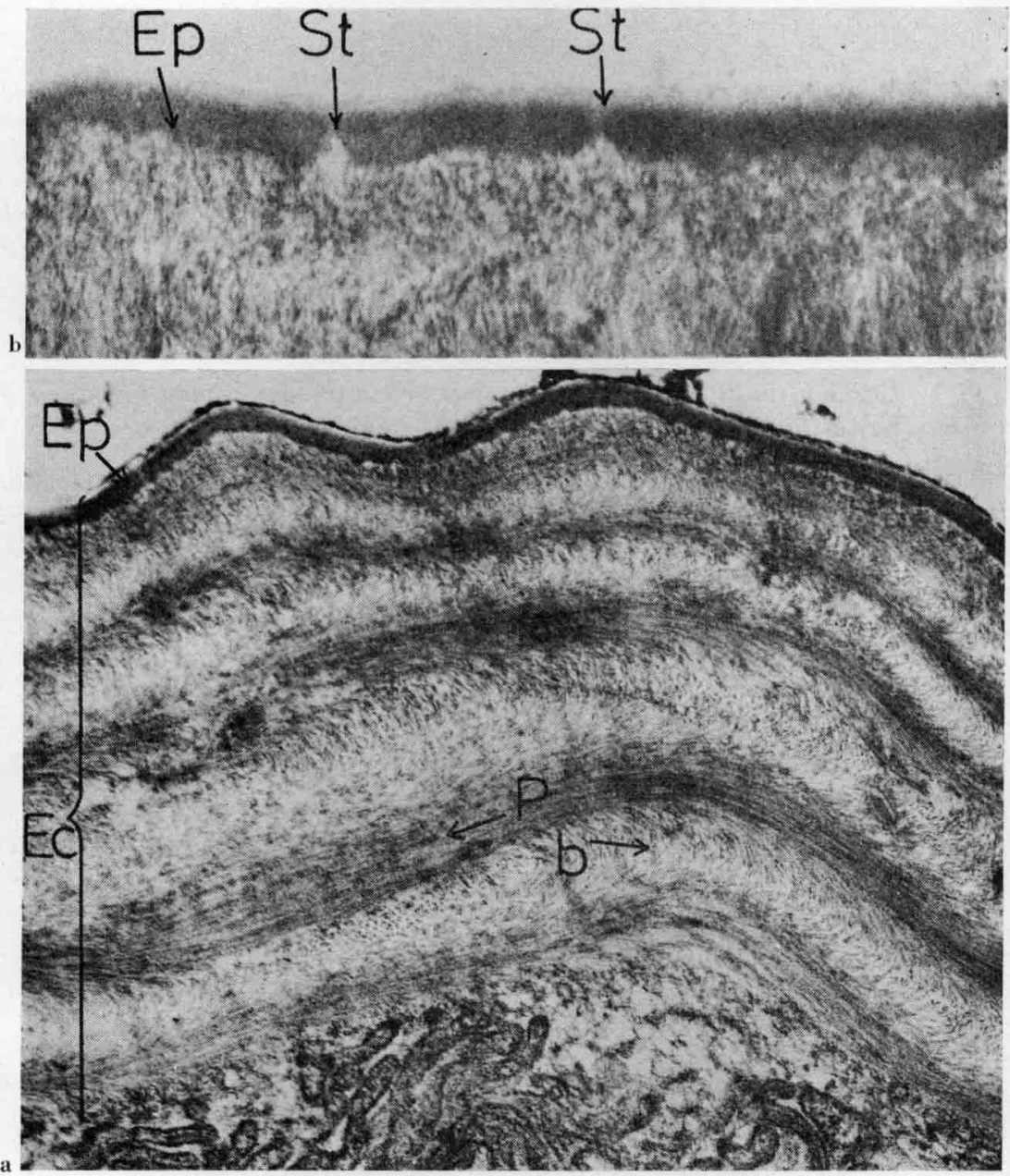

F. Ruttner, H. Enbergs, K. Kriesten 


\section{TAFEL IV}

Авв. 4. - Endocuticula aus Chitinfibrillen (F) mit dazwischenliegenden osmiophilen Granula (Gr). Elektronenlichte Stellen (e). x 84,000.

Aвв. 5. - Apikale Membraneinfaltungen am Thecaepithel einer einjährigen, legenden Königin (M), Endocuticula (Ec), osmiophile Granula (Gr). x 52500.

\section{PLANCHE IV}

Fig. 4. - Endocuticule de fibrilles chitineuses (F) et grains osmiophiles (Gr). Surface de faible densité électronique (e). x 84000.

Fig. 5. - Repli apical de la membrane dans l'épithélium de la thèque d'une reine féconde et en ponte d'un an (M), endocuticule (Er) grain osmiophile (Gr). x 52500 . 

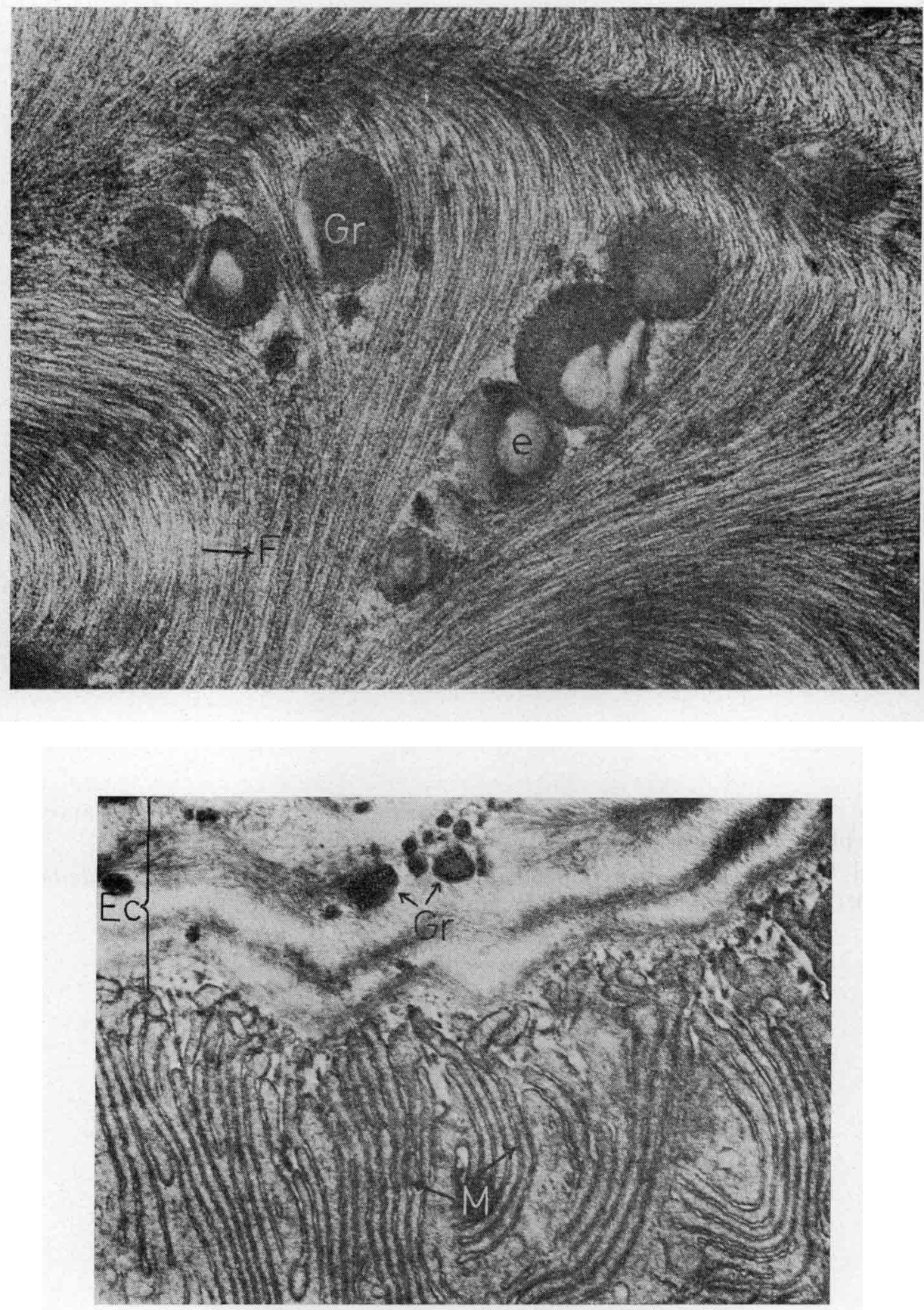

F. Ruttner, H. Enbergs, K. Kriesten 


\section{TAFEL $\quad V$}

Aвв. 6. - a) Epithelzellkontakt im apikalen Bereich.

Desmosom (D), Membraneinfaltungen (M), Lysosom (L), Microbody (Mb). x 21000 .

b) Apikal-basal orientierte, vorwiegend längliche Mitochondrien (Mi), Membraneinfaltungen (M), Cuticula (C). x 21000.

\section{PLANCHE V}

Fig. 6. - a) Contact de cellule épithéliale dans le secteur apical. Desmosome (D), repli de la membrane (M), lysosome (L), Microbody (Mb). x 21000.

b) Mitochondries principalement allongées avec orientation apicale-basale (Mi), repli de la membrane (M), Cuticule (C). x 21000. 


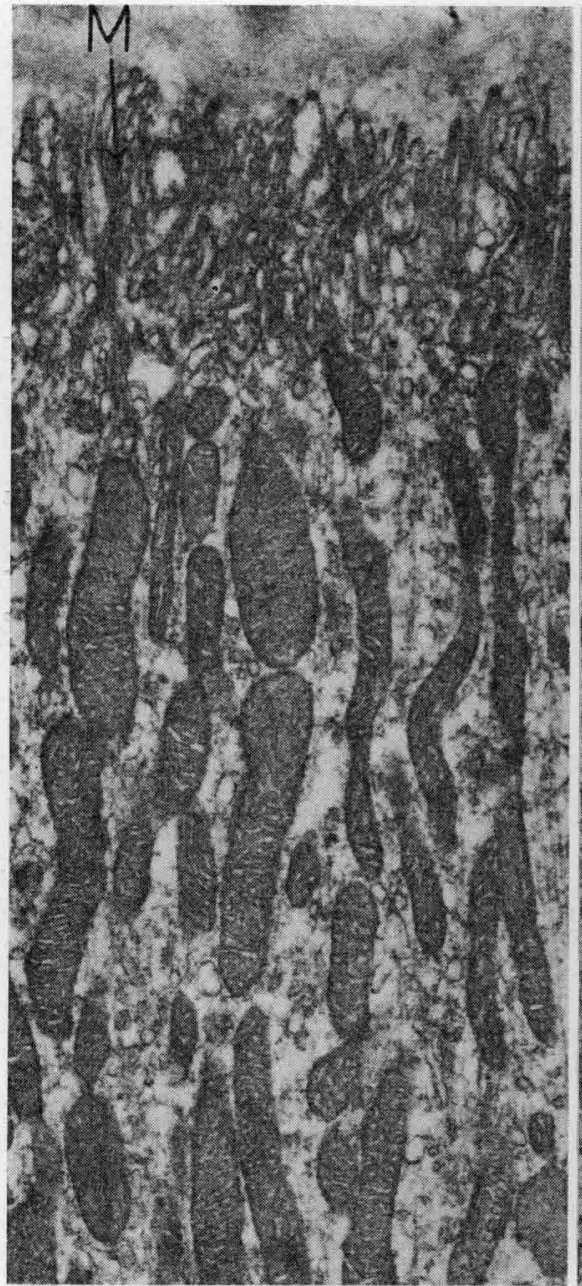

a

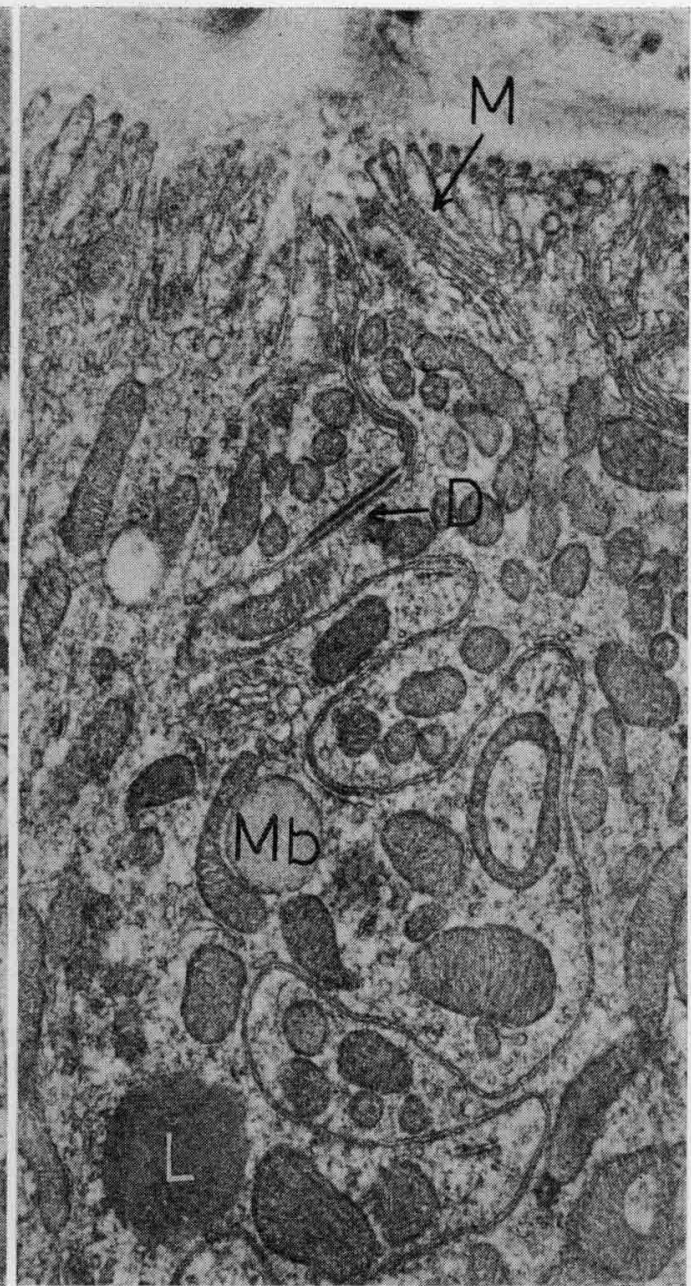

b

F. Ruttner, H. Enbergs, K. Kriesten 


\section{TAFEL VI}

Авв. 7. - а) Basale Epithelzone des Thekaepithels einer 2 Tage alten unbegatteten Königin.

Basale Membraneinfaltungen (M), vorwiegend rundliche Mitochondrien (Mi), Basalschicht (B). x 17500.

b) Basale Epithelzone des Thekaepithels einer vor 3-5 Monaten begatteten Königin.

Basale Membraneinfaltungen (M), vorwiegend längliche, membranassoziierte Mitochondrien (Mi), Basalschicht (B), osmiophile Globuli (oG), Lysosome (L), Tracheolenwand (Tr). x 17500.

\section{PLANCHE VI}

FIG. 7. - a) Zone épithéliale basale de l'épithélium de la thèque d'une reine vierge de 2 jours. Repli basal de la membrane (M), mitochondries principalement arrondies $(\mathrm{M} i)$, couche basale (B). x 17500 .

b) Zone épithéliale basale de l'épithélium de la thèque d'une reine fécondée de 3 à 5 mois. Repli basal de la membrane (M), Mitochondries principalement allongées et associées en membrane (Mi), Couche basale (B), globule osmophile_(oG), lysosome (L), paroi trachéolaire (Tr). x 17500. 
Apidologie, 1971, 2 (1).

P1. VI

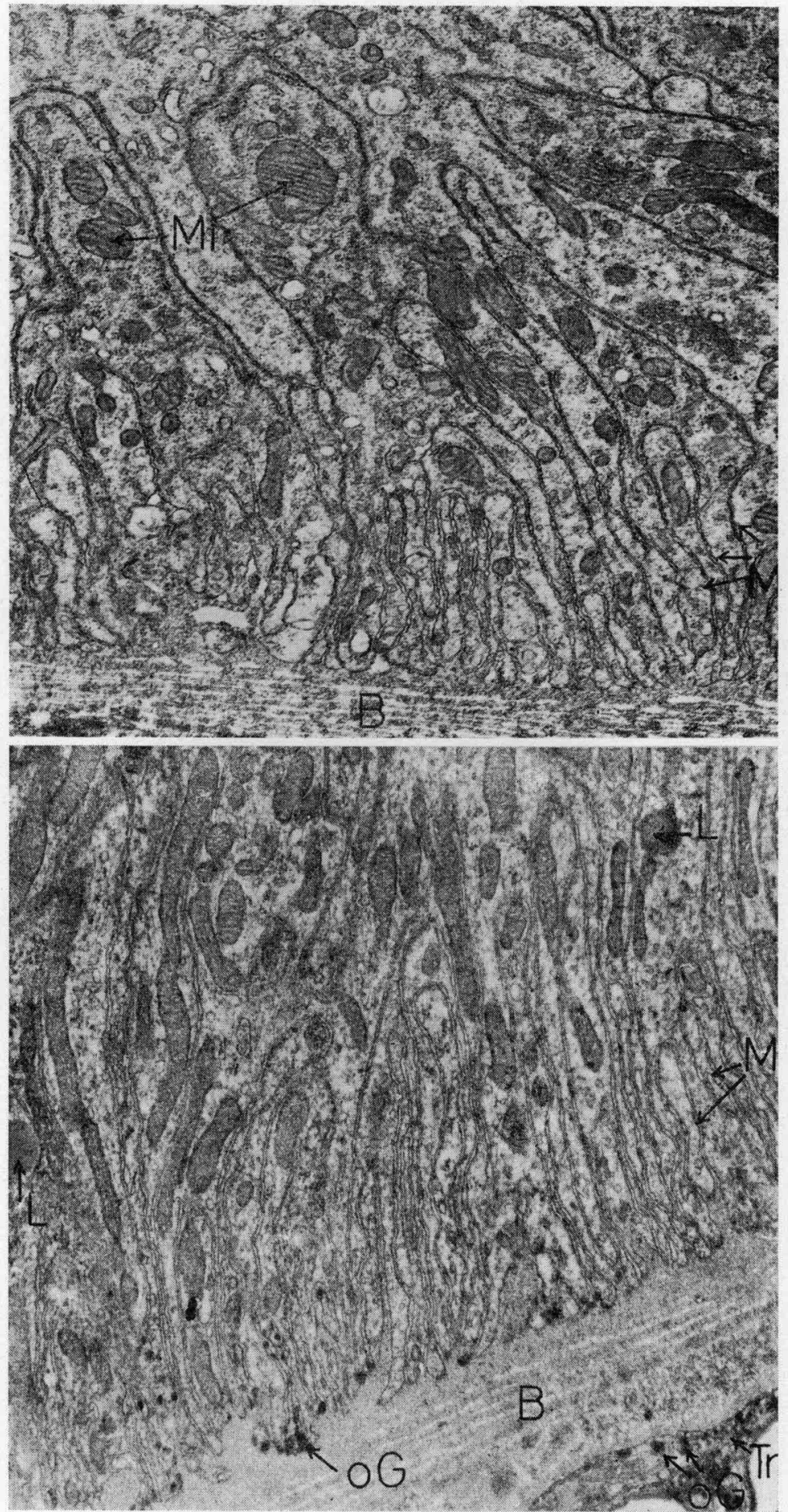

F. Ruttner, H. Endergs, K. Kriesten 
Aв8. 8. - a) Großes polymorphes Mitochondrium mit Degenerationserscheinungen. Zytoplasmamembranen mit regelmäßigen Querbrücken. $x 42000$. b) Großer osmiophiler Körper mit fibrillären und kristallinen Innenstrukturen. $\times 52500$.

\section{PLANCHE VII}

Fig. 8. - a) Mitochondrium grand et polymorphe avec signes de dégénérescence. Membranes cytoplasmiques avec ponts obliques réguliers. $\times 42000$.

b) Grand corps osmiophile avec structure interne fibrillaire et cristalline. $x 52500$. 


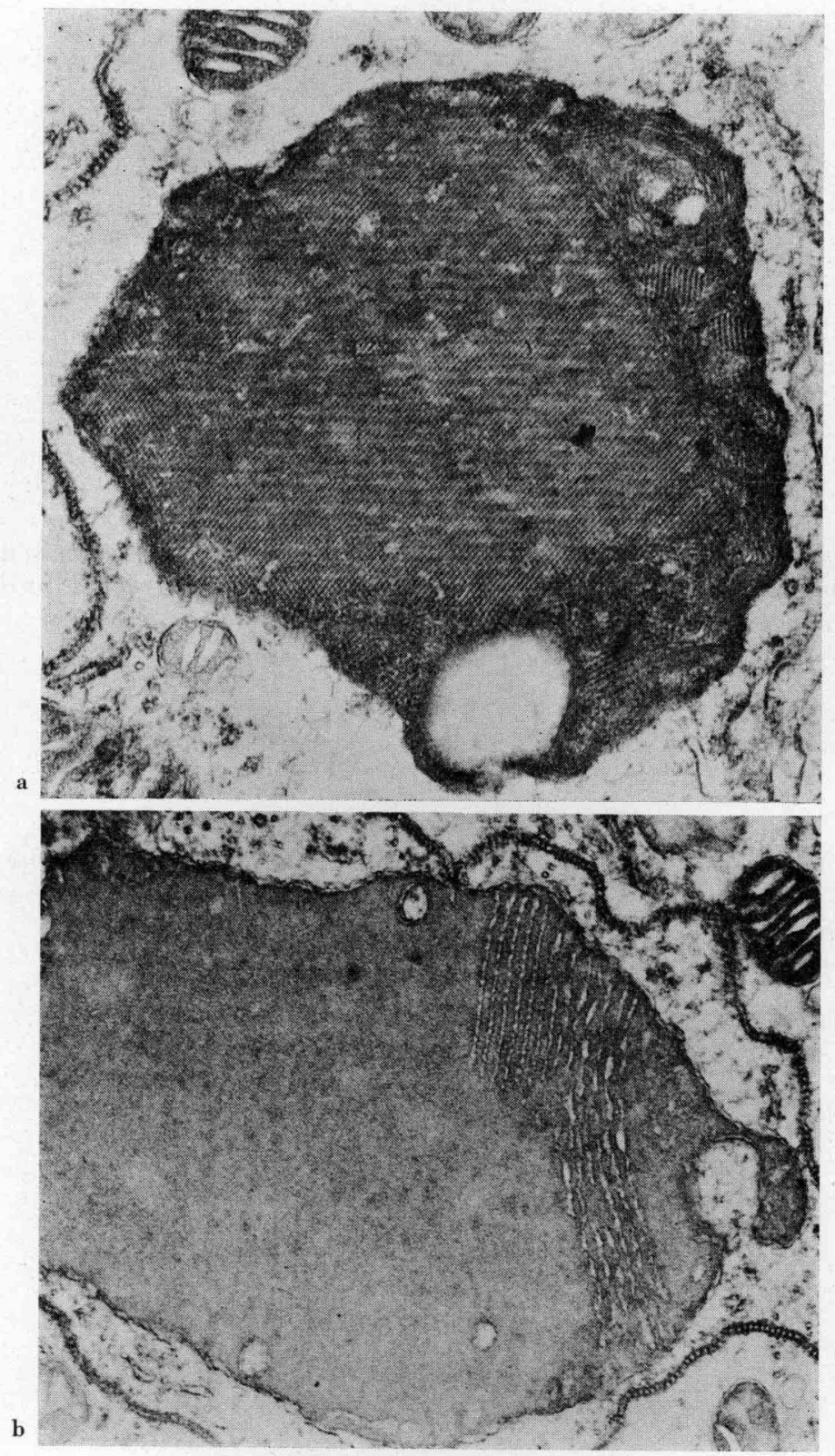

F. Ruttner, H. Enbergs, K. Kriesten 


\section{TAFEL VIII}

ABB. 9. - Komplex geformte osmiophile Körper mit kristallinen Innenstrukturen im Thekwepithel einer einjährigen, legenden Königin. Osmiophile Granula $(o G)$. a) $\times 17500, b) \times 68850$.

\section{PLANCHE VIII}

Fig. 9. - Corps osmiophile de forme complexe avec structure interne cristalline dans l'épithelium de la thèque d'une reine féconde en ponte d'un an. Granule osmiophile (oG).
a) $\times 17500$.
b) $\times 68850$. 


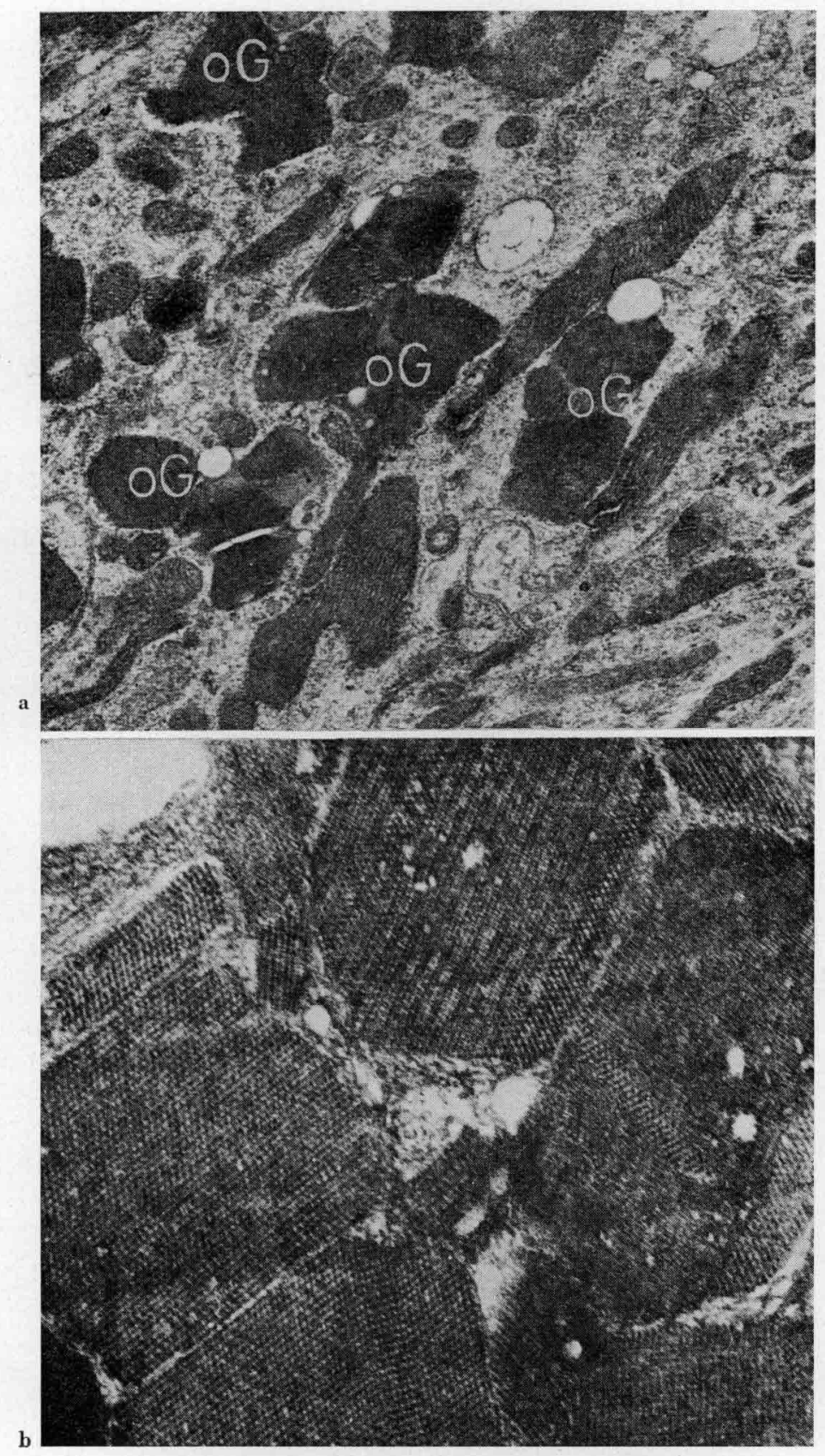

F. Ruttner, H. Enbergs, K. Kriesten 


\section{TAFEL IX}

Aвв. 10. - Microbodies (Abb. a) bzw. Cytolysosome (Abb. b u. c.). Microtubuli in Abb. a (Mt). x 21000.

Aвв. 11. - Ausschnitt aus dem Spermathekaepithel einer 4 Tage alten unbegatteten Königin.

Cuticula (C), apikale Membraneinfaltungen (M), Kern (N), Nukleoli (Nu). x 10000 .

\section{PLANCHE IX}

Fig. 10. - Microbodies (Fig. a) respectivement cytolysosome (Fig. b et c). Microtubuli dans la fig. $a(\mathbf{M} t) . \times 21000$.

Fig. 11. - Coupe dans l'épithélium de la spermathèque d'une reine vierge de 4 jours. Cuticule $(c)$, repli apical de la membrane $(M)$, noyau $(N)$, nucléoles $(\mathrm{N} u) . \times 10000$. 

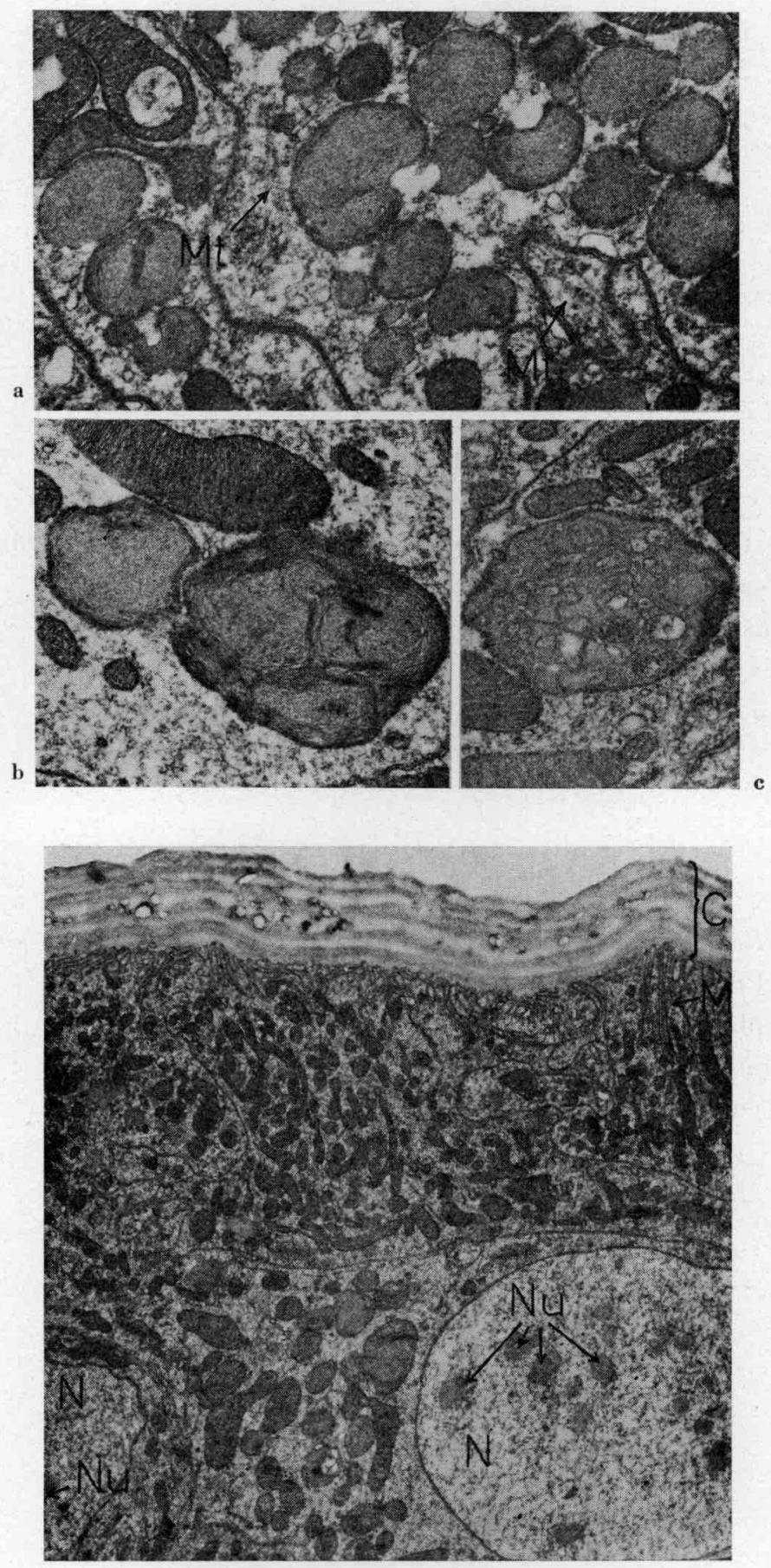

F. Ruttner, H. Enbergs, K. Kriesten 


\section{TAFEL $\mathrm{X}$}

AвB. 12. - Cytochemische Reaktionen am Epithel legender Königinnen. a u. b) saure Phosphatase,

c) alkalisehe Phosphatase,

d) Peroxidase.

Vergr. $a$ u.c) $\times 17500, b) \times 63000, d) \times 28000$.

\section{PLANCHE X}

Fic. 12. - Réactions cytochimiques sur l'épithélium d'une reine ên ponte. $a$ et $b)$ Phosphatase acide.

c) Phosphatase alcaline.

d) Peroxydase.

Grossissement : a et $c$, x $17500, b$, x $63000, d, \times 28000$ : 

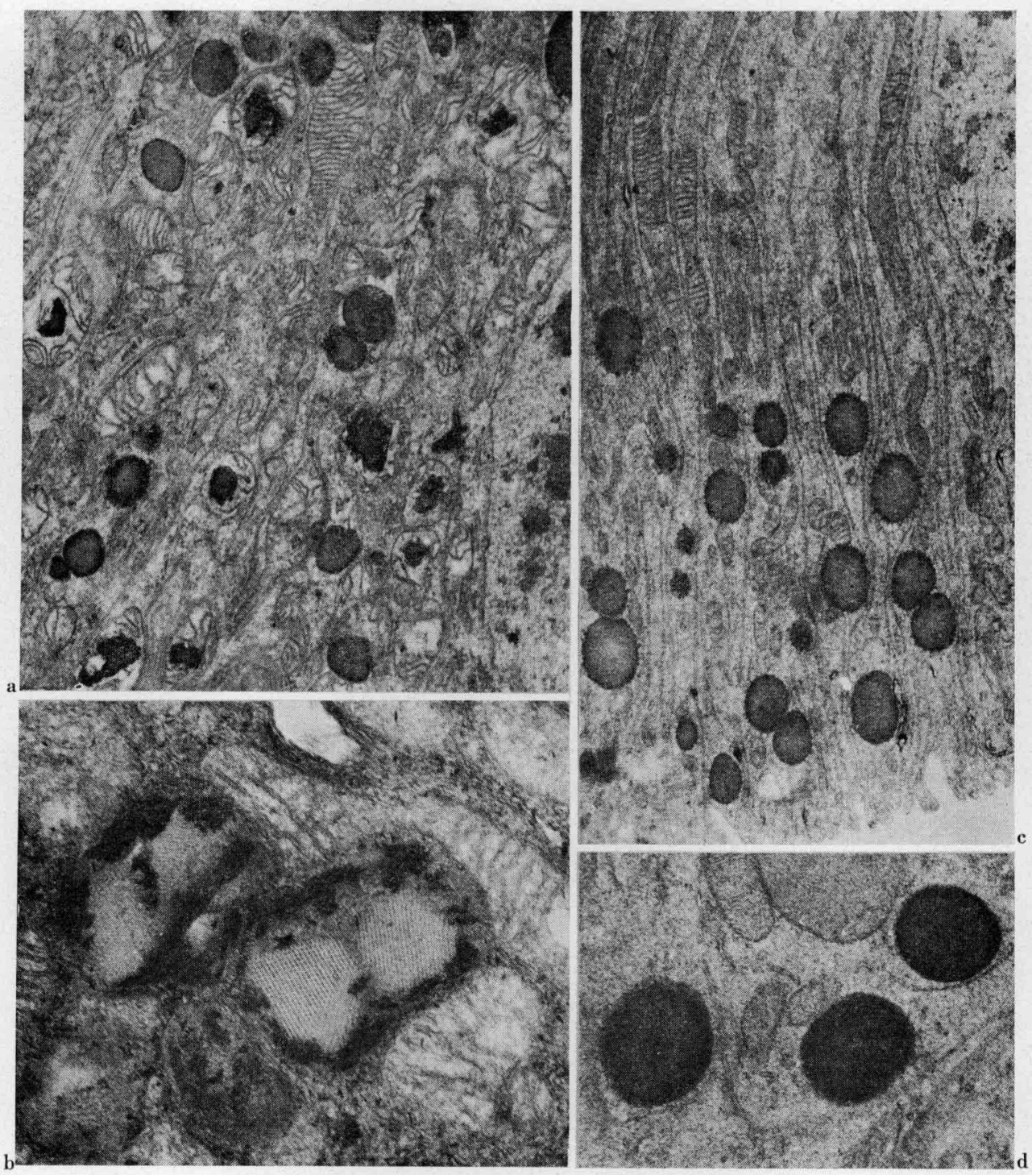

F. Ruttner, H. Enbergs, K. Kriesten 